\title{
Thermoplastic Cable Insulation Comprising a Blend of Isotactic Polypropylene and a Propylene-ethylene Copolymer
}

\author{
C. D. Green, A. S. Vaughan \\ Tony Davies High Voltage Laboratory \\ University of Southampton, UK \\ G. C. Stevens, A. Pye \\ GnoSys Global \\ Guildford, UK \\ S. J. Sutton \\ EPRI, \\ Egham, UK \\ T. Geussens \\ Dow Europe GmbH \\ Horgen, Switzerland \\ and M. J. Fairhurst \\ National Grid, Warwick, UK
}

\begin{abstract}
There is much interest in the development of replacement materials for crosslinked polyethylene (XLPE) that are both recyclable (i.e. thermoplastic) and capable of high temperature operation. Thermally, polypropylene is the ideal choice, although its stiffness and low electrical breakdown strength make for a challenging materials design problem. We report here on the compositional optimization of a propylene homopolymer/propylene-ethylene copolymer blend in terms of its dynamic mechanical properties and thin film electrical breakdown strength. The extrusion of a trial minicable using the optimized blend is also discussed, which is shown to exhibit a significantly improved electrical performance, as gauged by its DC breakdown strength, than an XLPE-insulated reference.
\end{abstract}

Index Terms - Cables, polypropylene, copolymer, polymer blends, insulation, dielectric breakdown, mechanical properties, recyclable.

\section{INTRODUCTION}

TOGETHER with its high breakdown strength $\left(E_{b}\right)$ and low dielectric loss, crosslinked low density polyethylene (XLPE) exhibits good high temperature mechanical properties. As such, it can be operated continuously at up to $90{ }^{\circ} \mathrm{C}$ and, under short circuit conditions, for a few seconds with conductor temperatures over $200{ }^{\circ} \mathrm{C}$. As a result of this combination of electrical and mechanical characteristics, XLPE has a long history of use in high voltage AC (HVAC) cable applications and, increasingly, the same underlying materials technology is being refined for use in HVDC cable designs.

However, increasing environmental consciousness has led, on the one hand, to the development of XLPE recycling technologies [1] and, on the other, to the development of novel thermoplastic materials [2]. In addition to recyclability, the use of thermoplastics also brings further benefits in that cables can be manufactured more quickly in a one-shot process with no crosslinking or degassing and higher material purities can be reached through the use of finer melt filters and the absence of crosslinking by-products. In thermoplastics, there is no risk of amber generation due to premature crosslinking [3].

In a previous paper [4], we discussed the practical manufacture of a cable employing insulation based upon a 20 wt:80wt blend of high density (HDPE) and low density polyethylene (LDPE). In comparison with XLPE, this system exhibited both an enhanced AC ramp breakdown strength over a wide temperature range and a reduction in the rate at which the mechanical modulus decreased with increasing 
temperature. However, such a blend still softens as its maximum working temperature of $\sim 120^{\circ} \mathrm{C}$ is approached.

In contrast, isotactic polypropylene (iPP) has a melting temperature of $\sim 170{ }^{\circ} \mathrm{C}$, albeit that it is too stiff and brittle for application in cables and has a low $E_{b}$ due to the influence of distinct spherulite boundaries [5]. The use of blends of iPP with softer, compatible polymers presents, in principle, a solution to these mechanical deficiencies. Indeed, propylenebased systems with high breakdown strengths and improved flexibility have been produced with syndiotactic PP, albeit that the high temperature operating limit of this material offers few benefits over many PE-based systems and blending with softer polymers is still required to counteract the problem of low temperature brittleness [5].

The elegance of the polyethylene (PE) blend system described above stems from the crystallization process, in which lamellae grow through rejected molten impurities, such that defective material does not become concentrated at spherulitic boundaries [6-8]. Indeed, the concept of distinct interspherulitic regions is then somewhat redundant, in that lamellae from adjacent spherulites form interlocking structures containing a high density of tie molecules, with electrically weaker moieties being distributed throughout the system. We do not believe that comparable mechanisms of morphological evolution have been successfully developed in propylenebased systems, the closest analogue being the work of Lustiger et al. [9]. In this study, a specially designed iPP/propyleneethylene copolymer blend was chosen, in which excess copolymer at spherulite boundaries was found to co-crystallize with the iPP lamellae in such a way as to increase the effective tie molecule density, improving the balance of properties required for successful application in power cables.

A crude means of obtaining acceptable mechanical behavior in iPP blends is simply to use heterophasic systems. These can be prepared either by mechanical blending or by direct polymerization [10]. One such catalyst alloy system, Hifax $10 \mathrm{~A}$ from LyondellBasell Polyolefin, has been found to exhibits a higher breakdown strength than XLPE. However, when blended with iPP to achieve the desired stiffness for cable manufacture, the resulting $E_{b}$ was found to be less than $60 \%$ that of XLPE [11]. Indeed, even if the heterophasic morphology does not directly reduce $E_{b}$, the inherent material inhomogeneity is likely to provide a source of weak spots for electrical aging processes.

The compatibility of iPP with random propylene-based copolymers is dependent on the copolymer composition and the size and structure of the co-monomer unit. The resulting blend systems exhibit a range of miscibilities, with the ultimate textures being dependent on the degree to which liquid/liquid phase separation (LLPS), solid/liquid phase separation (SLPS) and co-crystallization occur [12]. The interactions in a blend between copolymer and homopolymer segments during co-crystallization is dependent not only on the overall copolymer composition, but also on the precise sequence of units along the chain, which is largely determined by the catalyst system used during synthesis. This sensitivity ultimately manifests itself in the physical properties of the resulting material, hence the progressive move from Ziegler-
Natta to metallocene catalysis, due to the greater control that stems from the latter catalyst type [13].

The study described here set out to evaluate the potential of propylene-based thermoplastic blends for use as next generation cable insulation materials. The rationale behind this is as follows: being thermoplastic, such materials are readily recycled at the end of life. Also, removing the need to include the crosslinking step reduces energy consumption during cable manufacture (lower temperatures during production and no degassing step). As such, the technology has the potential to be "greener" than existing XLPE based systems. However, for such a thermoplastic blend to supersede XLPE, then it must exhibit a combination of electrical and mechanical properties that surpass those of XLPE. Then, we envisage that with suitable refinement, a range of blend variants may be used in both AC and DC applications, just as XLPE is used now. To demonstrate the validity of the fundamental concept, the work was divided into phases. First, a study of the effect of molecular composition on morphological evolution, electrical breakdown behavior and mechanical characteristics of propylene-based blends was undertake in the laboratory, in the form of thin film and plaque specimens. The objective of this initial phase was to define the most promising system, based upon relative electrical (high breakdown strength) and mechanical performance (i.e. good low temperature flexibility; good high temperature mechanical integrity, to give maximum flexibility in terms of system operation). While it may be possible to define a promising material in the laboratory, this fails to deal with two critical issues: is it possible to extrude such a system to give a cable and does the cable still exhibit desirable characteristics? Consequently, in the second phase of the work, an optimal blend composition was used to produce a trial mini-cable, which was characterized in terms of morphology and breakdown performance. In this case, the electrical performance of an equivalent XLPE-insulated minicable was used as a benchmark.

\section{EXPERIMENTAL PROCEDURES}

\subsection{POLYMER BLENDING}

The iPP used in this study was the Dow H358-02 system, which is synthesized using a standard Ziegler-Natta process. Initial laboratory studies were undertaken using solution blends comprising various weight \% (wt $\%$ ) of this polymer with one of three metallocene-catalyzed propylene-ethylene copolymer systems; VERSIFYTM 2200, 2300 and 2400 contain 9, 12 and $15 \mathrm{~mol} \%$ of ethylene respectively. The blend components were added to stirred, boiling xylene at a level of $\sim 2 \mathrm{wt} \%$ and left to dissolve for $20 \mathrm{~min}$. Subsequent precipitation was obtained by slowly adding the solution to an equal quantity of methanol at a starting temperature of $\sim 4^{\circ} \mathrm{C}$. The resulting gel was filtered overnight at room temperature before being dried for $30 \mathrm{~min}$ in an oven at $200{ }^{\circ} \mathrm{C}$ under a continuous dry nitrogen purge. This final step was used as a precaution against macroscopic phase separation, in line with experience gained by the authors using similar blend systems. For comparison, additional melt-mixed blends were also prepared in the laboratory, using a Brabender Plastograph with a W50EHT mixing attachment. For this, $36 \mathrm{~g}$ of the required 
mixture of polymer pellets were placed in the preheated mixing chamber, the mixing speed was set to $30 \mathrm{rpm}$, the temperature was set to $170{ }^{\circ} \mathrm{C}$ and the system was mixed for $20 \mathrm{~min}$. Finally, approximately 1 ton of the blend chosen for mini-cable manufacture (50:50 wt:wt iPP/VERSIFYTM 2200) was produced by Dow using a Berstorff ZE40UT twin screw extruder.

Throughout this paper, the various blend systems are designated as follows: (S/M/E)(2200/2300/2400)(50/37.5), where the first letter indicates solution blending (S), melt blending (M) or extrusion (E), the middle number indicates the member of the VERSIFYTM series used in the blend and the final number defines the percentage iPP by $\mathrm{wt} \%$. All blends were checked for homogeneity by taking eight randomly selected $15 \mathrm{mg}$ samples and crystallizing them in a differential scanning calorimeter (DSC) by cooling from $200{ }^{\circ} \mathrm{C}$ at $10{ }^{\circ} \mathrm{C} \mathrm{min}^{-1}$. The variation in the enthalpy of the iPP crystallization peak was always found to be less than $10 \%$.

\subsection{MICROSCOPY}

An initial assessment of morphological development in the solution blends was obtained through optical examination of thin films $\sim 10 \mu \mathrm{m}$ in thickness, which were prepared on a glass slide by solution casting from xylene. For this, drops of polymer solution were progressively added to the slide until a continuous film was obtained. Then, a cover slip was added and lightly pressed onto the film on a hotplate set at $\sim 200{ }^{\circ} \mathrm{C}$. The resulting samples were isothermally crystallized in a Mettler hot-stage at $126^{\circ} \mathrm{C}$ for $30 \mathrm{~min}$. DSC was used to confirm that this period was sufficient to ensure isothermal crystallization to completion in all materials. The resulting slides were examined in transmission using a Leitz Aristomet polarizing optical microscope, with the transmission directions of the polarizer and analyzer oriented at $45^{\circ}$ to one another. This non-standard optical arrangement was adopted since it provided an optimal combination of birefringence and scattering contrast, which are respectively related to the spherulitic texture and phase separation effects.

Examination of etched, internal surfaces was carried out using a JEOL JSM-5910 scanning electron microscope (SEM). Internal surfaces were first exposed using an RMC CR21/MT7 cryo-ultramicrotome before being etched for $2 \mathrm{~h}$ in a $1 \% \mathrm{w} / \mathrm{v}$ solution of potassium permanganate in a mixture composed of 5 parts concentrated sulphuric acid to 2 parts orthophosphoric acid to 1 part water [14-16].

\subsection{THIN FILM BREAKDOWN TESTING}

Thin film samples were prepared between aluminium foils in accordance with the procedure described elsewhere [4]. Following initial pressing, the samples were either crystallized by quenching or by being subjected to the required controlled cooling program in the hot-stage. A range of different cooling regimes was used in order to vary both the time for which each specimen was held in the melt and the subsequent rate of crystallization. Finally, the aluminium foils were removed.

The above specimens were subjected to electrical testing using our standard AC ramp testing methodology. The objective of this was to subject all formulations to the same proven testing methodology and, thereby, determine the system that exhibited the best relative performance. This composition would subsequently be used in the manufacture of the mini-cable. Samples were inserted into a specially designed testing chamber containing Dow Corning 200/20cs silicone fluid. A sinusoidal $50 \mathrm{~Hz}$ voltage was applied to the sample with a peak-peak amplitude ramp of $141 \mathrm{~V} \mathrm{~s}^{-1} \pm 4 \%$ until breakdown. The thickness of the specimen was subsequently measured at each breakdown site such that the associated field, $E$, at breakdown could be determined. Each dataset, comprising at least 16 points, was analyzed using a 2parameter Weibull distribution $[17,18]$ :

$F(E)=1-\exp \left[-\left(\frac{E}{E_{b}}\right)^{\beta}\right]$

where $F(E)$ is the cumulative failure probability, $E_{b}$ is the scale parameter and $\beta$ is the shape parameters. $E_{b}$ and $\beta$ were calculated using the maximum likelihood estimation technique in the Reliasoft Weibull ${ }^{++} 7$ software and likelihood ratios were used to generate $90 \%$ confidence intervals.

\subsection{THERMAL ANALYSIS}

For dynamic mechanical thermal analysis (DMTA), plaque samples measuring $40 \mathrm{~mm}$ by $4 \mathrm{~mm}$ by $1.7 \mathrm{~mm}$ thick were prepared and analyzed using a Rheometrics RSA II DMTA, as described previously [4]. Melting traces were obtained from selected samples using a Perkin Elmer DSC7 differential scanning calorimeter using standard procedures [4].

\subsection{MINI-CABLE MANUFACTURE}

Mini-cable, with a nominal insulation thickness of $3.5 \mathrm{~mm}$, was manufactured on a Troester triple extrusion line; extrusion parameters are listed in Table 1. A 7-stranded aluminium conductor of cross-sectional area $25 \mathrm{~mm}^{2}$ was used together with DHDA-7707 BK for the inner semiconducting screen (semicon), which is a thermoplastic material supplied by Dow. Preliminary experiments had demonstrated that high voltage breakdown testing of such mini-cables could be conducted in two ways. First, a standard triple extrusion manufacturing process could be adopted, to give a cable with a conventional structure (conductor; semicon; insulation; semicon), whereupon, the complete length of the cable could be tested following the application of suitable terminations. This approach would generate the most reliable data, but the need to develop and apply appropriate terminations (capable of withstanding extremely high voltages) to a very large number of mini-cable samples would render this approach impracticable within the confines of this study. As such, an alternative methodology was devised, in which the mini-cable

Table 1. Extrusion conditions for cable manufacture.

\begin{tabular}{lcc}
\hline \multicolumn{1}{c}{ Parameter } & Blend & Inner semicon \\
\hline Screw speed $(\mathrm{rpm})$ & 45 & 10 \\
Melt temperature $\left({ }^{\circ} \mathrm{C}\right)$ & 195 & 182 \\
Line speed $\left(\mathrm{m} \mathrm{min}^{-1}\right)$ & 1.5 & 1.5 \\
Exit melt temperature $\left({ }^{\circ} \mathrm{C}\right)$ & 176 & 176 \\
Temperature in $\mathrm{CV}$ tube $\left({ }^{\circ} \mathrm{C}\right)$ & 83 & 83 \\
Temperature at cooling section exit $\left({ }^{\circ} \mathrm{C}\right)$ & 50 & 50 \\
\hline
\end{tabular}


was produced without an outer semicon, such that the testing methodology described below could be used. Since the objective of our study was to benchmark the propylene-based system against conventional XLPE, equivalent mini-cables were produced using the optimized propylene-based blend and XLPE and both were tested in the same way, to provide a relative measure of electrical performance.

\subsection{MINI-CABLE BREAKDOWN TESTING}

Ideally, the thin film and mini-cable breakdown testing would both have been undertaken using AC or DC stress. However, this proved doubly impracticable. From the point of view of thin film testing, the DC breakdown strength of these materials is several times higher than the AC strength. A compensatory decrease in sample thickness under AC would lead to large uncertainties in the applied field. Conversely, it was not possible to probe the AC breakdown strength of the mini-cables due to the onset of sustained surface discharge activity at $\sim 100 \mathrm{kV}$. As described above, it was not practicable to provide the necessary cable terminations to prevent this. Whilst it is admitted that DC breakdowns do not provide a direct comparison to the AC thin film studies [19], this does not negate the value of the HVDC tests in validating the concept of using these blends in practical cables.

Room temperature DC testing of the mini-cables was performed with a Henry Patterson \& Sons Ltd $600 \mathrm{kV}$ test set. $6 \mathrm{~m}( \pm 2 \%)$ lengths of cable were cut, crimped to form a loop and hung from a $3 \mathrm{~m}$ fiber-glass rod attached to a winch. The conductor was connected to the HVDC supply using a $2 \mathrm{~m}$ copper pipe; a trough of tap water formed the ground electrode.

The cables were divided into two batches of five samples. One batch was taken straight off the drum, the other was subjected to an extreme bend test by wrapping each cable length around a mandrel $12 \mathrm{~cm}$ in diameter for $2 \mathrm{~h}$, before relaxing for at least $16 \mathrm{~h}$ prior to testing. The primary objective of applying such a severe bend was to check the integrity of the conductor-semicon and semicon-insulation interfaces, with the added possibility of inducing damage in the crystalline structure of the blend. The $2 \mathrm{~h}$ application time was chosen in order that physical relaxation of the blend could occur prior to testing. A voltage ramp was then applied to each specimen in a stepwise fashion: $1.75 \mathrm{kV} \mathrm{s}^{-1}+/-13 \%$ rises for $8 \mathrm{~s}$, followed by $30 \mathrm{~s}$ dwells, in order to give an overall average ramp rate of $370 \mathrm{~V} \mathrm{~s}^{-1}+/-7 \%$. For safety reasons, it was not possible to apply a voltage greater than $400 \mathrm{kV}$ to the cables. The laboratory temperature throughout the tests remained constant at $16-17^{\circ} \mathrm{C}$.

\section{RESULTS}

\subsection{BLEND OPTIMISATION}

Figures 1 and 2 illustrate the effect of copolymer ethylene content on morphological evolution in propylene-based blends. In the case of the S2200/50 system, relatively slow isothermal crystallization, as occurs at $126{ }^{\circ} \mathrm{C}$, results in the formation of a well-defined spherulitic texture, which appears comparable to that of the homopolymer [20]. In contrast, S2400/50 exhibits clear evidence of a superimposed texture

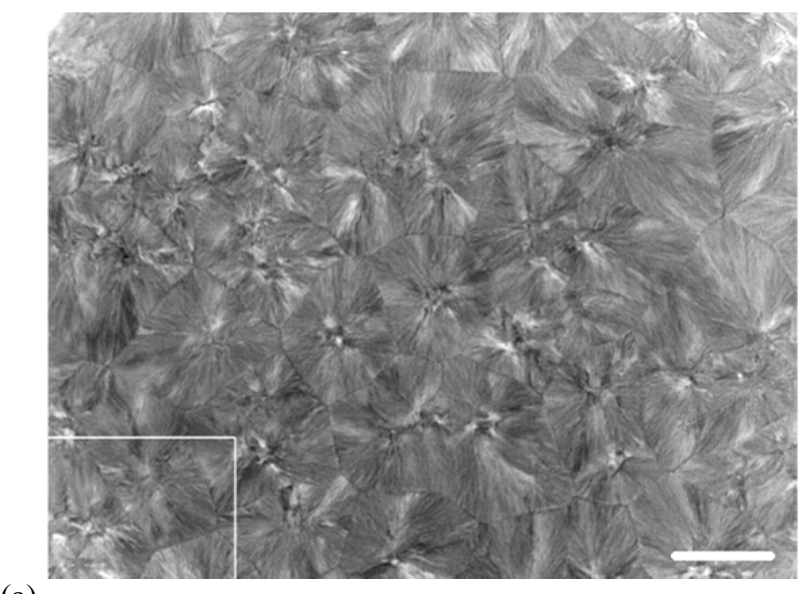

(a)

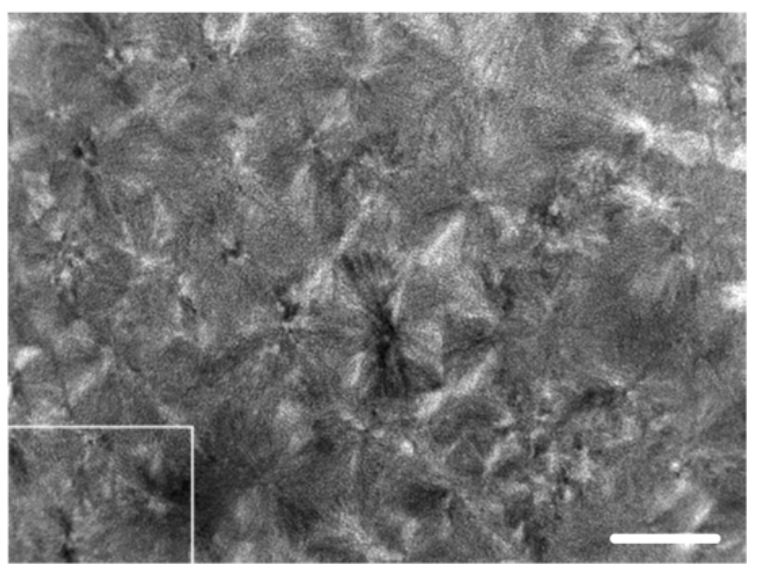

(b)

Figure. 1. Transmission optical micrographs showing (a) S2200/50 and (b) S2400/50 following isothermal crystallization at $126^{\circ} \mathrm{C}$. Phase separation on a scale $<10 \mu \mathrm{m}$ is observed only in S2400/50. Scale bar $50 \mu \mathrm{m}$.

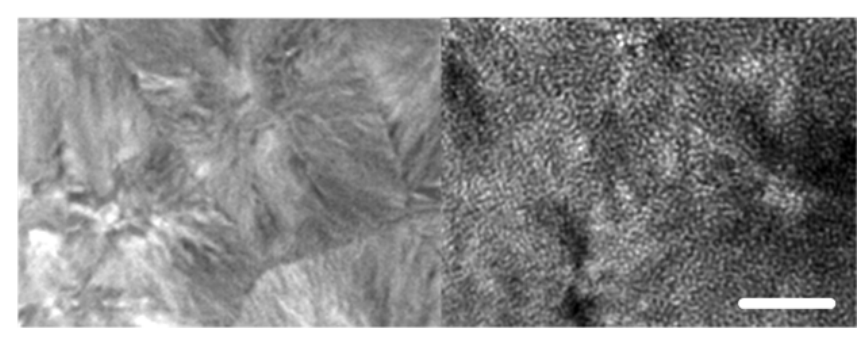

Figure 2. Higher magnification images corresponding to the white rectangles in Figure 1 showing samples of S2200/50 (left) and S2400/50 (right) after isothermal crystallization at $126^{\circ} \mathrm{C}$. Scale bar $20 \mu \mathrm{m}$.

(see Figure 2) that results from phase separation due to a degree of melt phase incompatibility between the two components of the blend. S2300/50 exhibits a morphology intermediate between these two extremes.

Figure 3 collates Weibull breakdown strength data obtained from thin film AC ramp breakdown testing of various specimens crystallized at an intermediate cooling rate $\left(1{ }^{\circ} \mathrm{C}\right.$ $\left.\mathrm{min}^{-1}\right)$. An optimal composition of $50 \mathrm{wt} \%$ iPP is apparent for all blends when testing is conducted at either $30{ }^{\circ} \mathrm{C}$ or $120^{\circ} \mathrm{C}$. At higher copolymer compositions, the behavior of the blends is dominated by the electrical characteristics of this blend component; the enhanced performance of VERSIFYTM 2200 


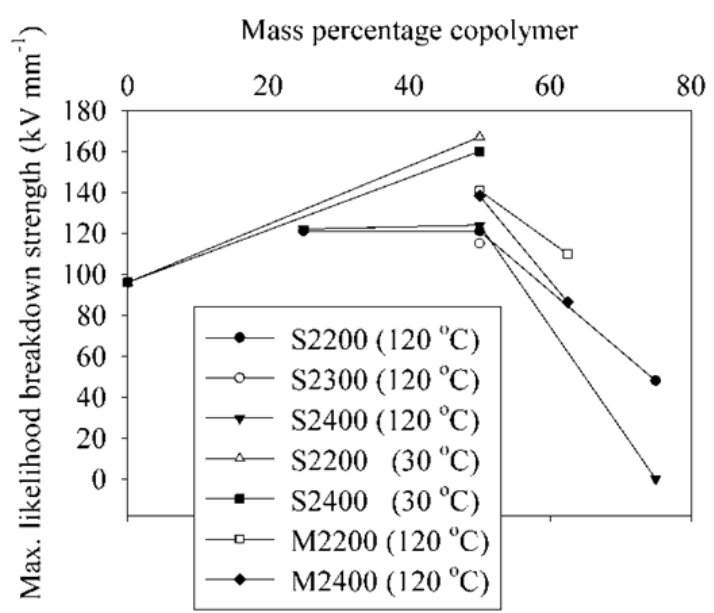

Figure 3. Maximum likelihood estimated Weibull location parameters for solution and melt-mixed blends crystallized at $1{ }^{\circ} \mathrm{C} \mathrm{min}-1$ and tested at the indicated temperatures.

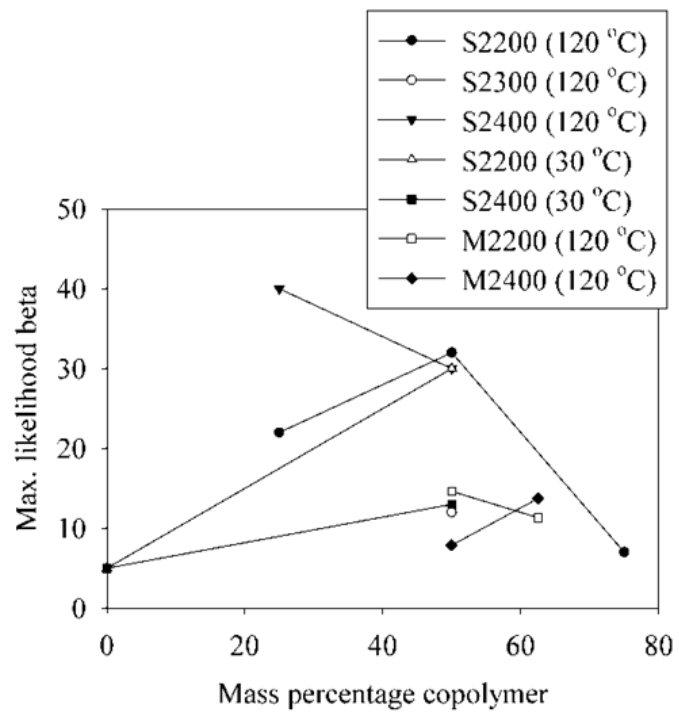

Figure 4. Maximum likelihood estimated Weibull shape parameters data for solution and melt-mixed blends crystallized at $1{ }^{\circ} \mathrm{C} \mathrm{min}-1$ and tested at the indicated temperatures.

in this regime compared with VERSIFYTM 2400 indicates that increasing the ethylene content of a propylene-ethylene copolymer results in materials with reduced electrical performance, at least when crystallized slowly. However, reducing the copolymer content below $50 \mathrm{wt} \%$ offers no further advantage. The spherulitic boundaries evident in Figure 1 are not unlike those in pure iPP and, consequently, at high iPP contents, we suggest that these dominate the observed behavior. Figure 4 presents Weibull shape parameter data for the systems discussed above. From this, it is evident that the melt-mixed blends exhibit rather lower $\beta$ values than the solution blends, an effect we attribute to the introduction of impurities and/or some thermal degradation during our laboratory melt-blending process.

In order to investigate the effect of thermal history on the thin film breakdown behavior of the melt blends, three cases were considered, all of which were tested at $120^{\circ} \mathrm{C}$. In Table 2, Samples 1-4 each has a thermal history that should
Table 2. Descriptions of thermal histories applied to blends for testing in Figures 5 and 6.

\begin{tabular}{|c|c|c|}
\hline $\begin{array}{l}\text { Label in } \\
\text { Figures } 5 \\
\& 6\end{array}$ & Material & Thermal history \\
\hline 1 & $50 / 2200$ & \multirow{4}{*}{$\begin{array}{l}\text { Hold @ } 200{ }^{\circ} \mathrm{C} \text { for } 2 \mathrm{~min} \text {, cool from } 140{ }^{\circ} \mathrm{C} \\
\text { to } 100{ }^{\circ} \mathrm{C} @ 1{ }^{\circ} \mathrm{C} \mathrm{min}^{-1} \text {, then cool naturally } \\
\text { to ambient. This thermal history was chosen } \\
\text { to mimic a reasonable cooling rate expected } \\
\text { for an extruded mini-cable. }\end{array}$} \\
\hline 2 & $50 / 2400$ & \\
\hline 3 & $37.5 / 2200$ & \\
\hline 4 & $37.5 / 2400$ & \\
\hline 5 & $50 / 2200$ & \multirow{4}{*}{$\begin{array}{l}\text { Cool from } 200{ }^{\circ} \mathrm{C} \text { to } 100{ }^{\circ} \mathrm{C} @ 0.1{ }^{\circ} \mathrm{C} \min ^{-1} \\
\text { then cool naturally to ambient. An } \\
\text { extremely slow cool which may promote } \\
\text { liquid-liquid phase separation in the melt as } \\
\text { well as enhanced molecular segregation } \\
\text { upon crystallization of the iPP. }\end{array}$} \\
\hline 6 & $50 / 2400$ & \\
\hline 7 & $37.5 / 2200$ & \\
\hline 8 & $37.5 / 2400$ & \\
\hline 9 & $50 / 2200$ & \multirow{4}{*}{$\begin{array}{l}\text { Hold @ } 200{ }^{\circ} \mathrm{C} \text { for } 2 \mathrm{~min} \text {, then quench into } \\
\text { tap water at } 5-15{ }^{\circ} \mathrm{C} \text {. An unrealistically fast } \\
\text { cooling event which would prevent any } \\
\text { electrical or mechanical benefit arising from } \\
\text { the spherulitic textures generated at } 1{ }^{\circ} \mathrm{C} \\
\min ^{-1}\end{array}$} \\
\hline 10 & $50 / 2400$ & \\
\hline 11 & $37.5 / 2200$ & \\
\hline 12 & $37.5 / 2400$ & \\
\hline
\end{tabular}

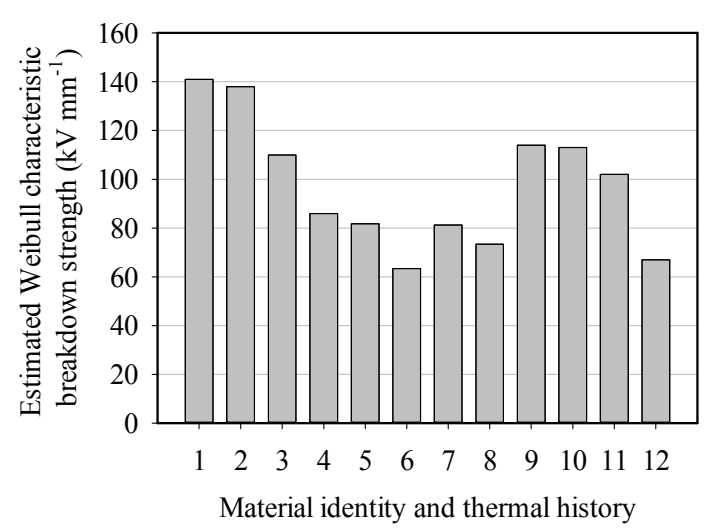

Figure 5. Effect of thermal history and blend composition on AC ramp breakdown strength. Crystallization at $1{ }^{\circ} \mathrm{C} \mathrm{min}-1$ yields higher breakdown strengths than both slow cooling and quenching.

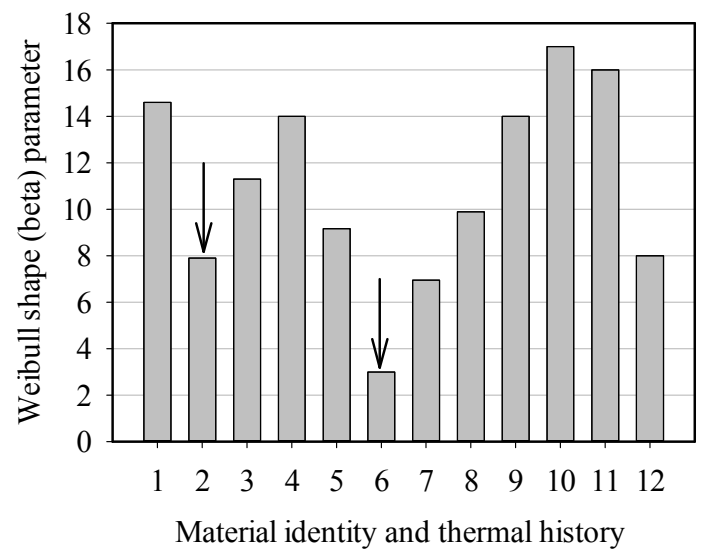

Figure 6. Weibull shape parameters corresponding to the data in Figure 5. Arrows indicate the tendency for M2400/50 to exhibit high scatter under low to moderate cooling rates. 
constitute a reasonable approximation to the crystallization conditions that would occur during mini-cable extrusion [4]; associated results constitute a subset of the same data discussed above. The remaining two groups of samples (5-8 and 9-12) represent extremes either side of this. Figure 5 demonstrates that the extremely low cooling rate $\left(0.1{ }^{\circ} \mathrm{C} \mathrm{min}-1\right)$ experienced by Samples 5-8 significantly reduces $E_{b}$. This could be a consequence of increased LLPS in the melt, or the development of a coarser crystal morphology during slow crystallization. However, rapid quenching, as imposed on Samples 9-12, results in a universal decrease in $E_{b}$ compared with crystallization at the intermediate rate. As such, it is evident that the systems considered here behave in a similar manner to the PE blend described previously [4]. Finally, Figure 6 helps us to confirm our choice of M2200/50 for extrusion: the shape parameter for M2400/50 is highly dependent upon cooling rate (see Samples 2 and 6 arrowed) and, unless quenched, is approximately half that of M2200/50.

From an electrical breakdown viewpoint, the system containing 50\% iPP and 50\% VERSIFYTM 2200 appears close to optimal, as far as the various material combinations considered in this study are concerned. However, any practically viable cable material must also exhibit reasonable low temperature flexibility and high temperature thermomechanical integrity and, consequently, the question remains as to whether or not this constitutes an appropriate composition from a mechanical perspective. Figure 7 compares the thermo-mechanical response of XLPE with a range of blend systems in which the crystallization conditions, $\left(1{ }^{\circ} \mathrm{C} \mathrm{min}{ }^{-1}\right.$ or $\left.20^{\circ} \mathrm{C} \mathrm{min}^{-1}\right)$, blend composition $(37.5 \%$ or $50 \%$ iPP) and copolymer (VERSIFYTM 2200 or 2400) have been adjusted. From this, it is evident that all the systems studied are comparable to XLPE in terms of their low temperature stiffness and that significant variations in this cannot be achieved in the propylene-based systems by increasing the level of copolymer in the blend or by increasing the amount of ethylene in the copolymer. That is, the low temperature mechanical response of the system does not conform to any simple mixing rule.

This point is further reinforced at high temperature, where the behavior of M2400/50 and that of M2400/37.5 are particularly interesting. Above $100{ }^{\circ} \mathrm{C}$, the increasing difference in modulus between the blend components makes the overall stiffness increasingly dependent on the topology of the crystalline structure as set in the context of a liquid-liquid phase separated background. Indeed, the excellent high temperature rigidity of M2400/37.5 is remarkable, given that it contains the highest proportion of the most flexible copolymer. We are unaware of any treatment of this topic in the literature, though it may have huge value in the design of polymer systems for cables with tailored temperaturedependent mechanical properties. To conclude, although the range of compositions and copolymer types considered here does not constitute a comprehensive mechanical study, as a result of the electrical constraints discussed above, the mechanical data contain nothing to indicate that a combination of $50 \%$ iPP and 50\% VERSIFYTM 2200 would be inappropriate for mini-cable production.

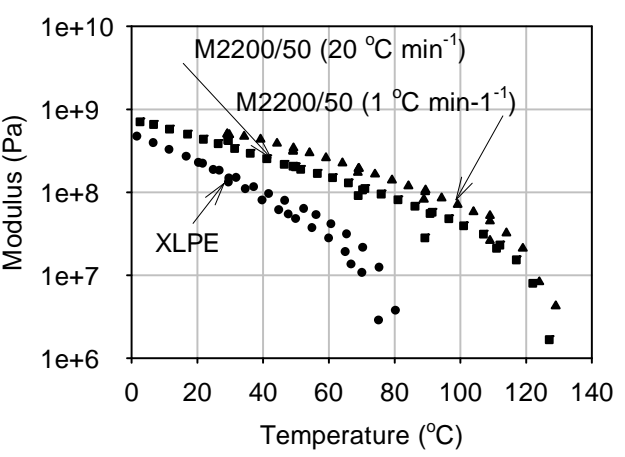

(a)

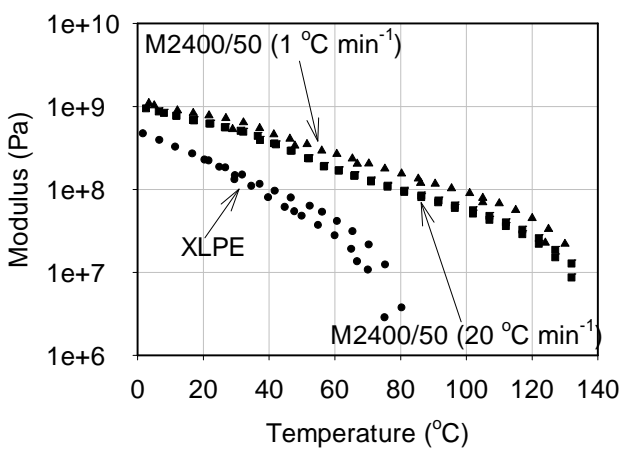

(b)

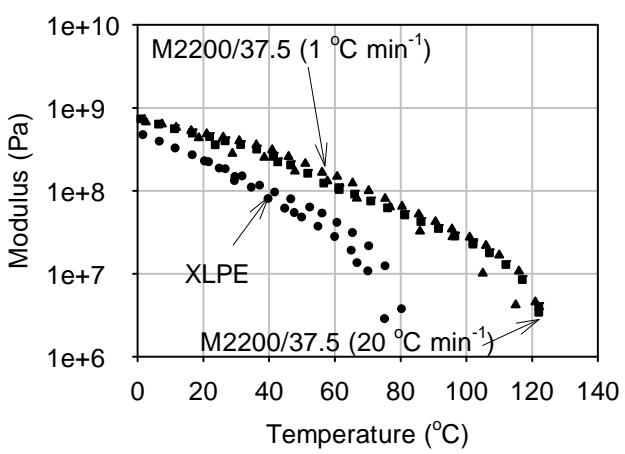

(c)

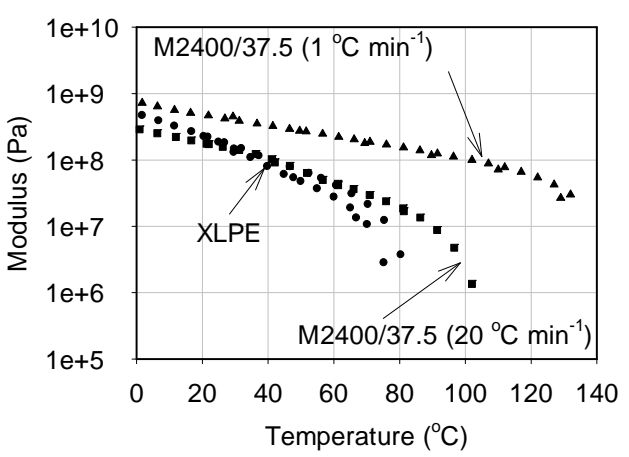

(d)

Figure 7. DMTA data from melt-mixed blends obtained following crystallization at $1{ }^{\circ} \mathrm{C} \mathrm{min}{ }^{-1}$ and $20^{\circ} \mathrm{C} \mathrm{min}^{-1}$. One independent sample per dataset; XLPE data are identical in all graphs. Reducing the iPP content gives no reduction in low temperature stiffness over the compositional range studied. 


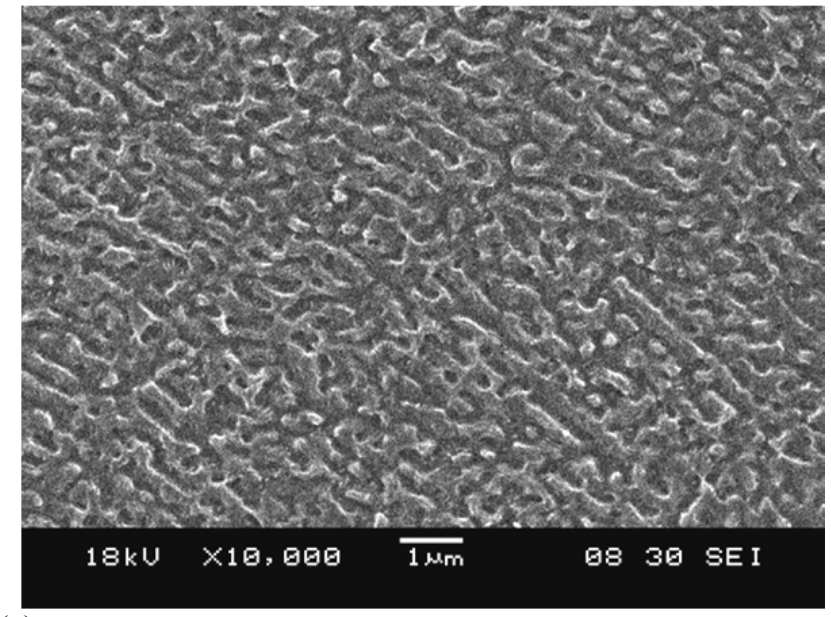

(a)

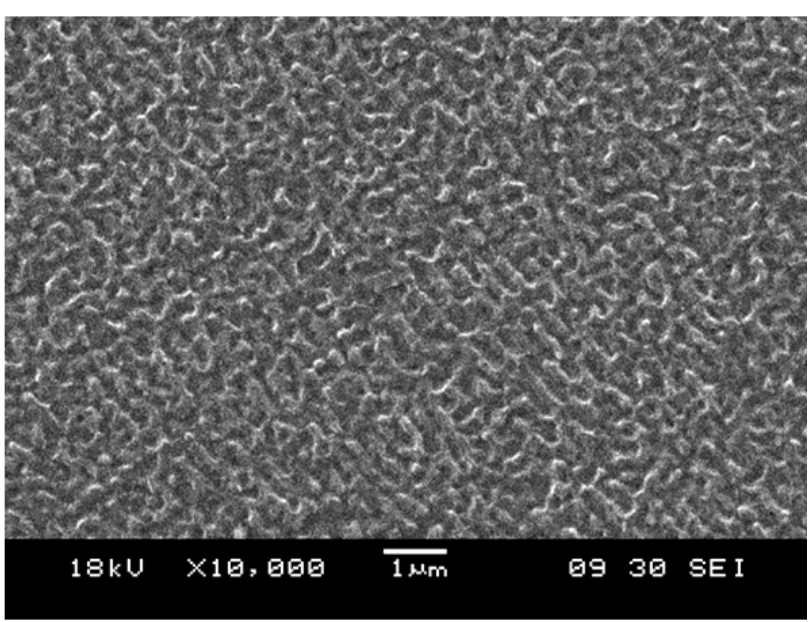

(b)

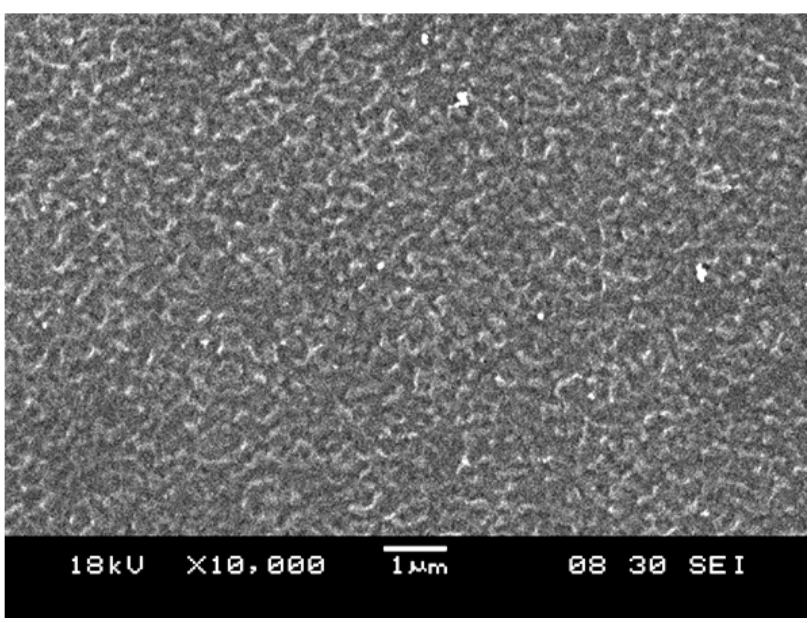

(c)

Figure 8. SEM micrographs showing the structure of specimens of the blend E2200/50 that were melted at $200{ }^{\circ} \mathrm{C}$ and then crystallized by cooling from $140{ }^{\circ} \mathrm{C}$ to $100{ }^{\circ} \mathrm{C}$ at (a) $1{ }^{\circ} \mathrm{C} \mathrm{min}{ }^{-1}$, (b) $3{ }^{\circ} \mathrm{C} \mathrm{min}^{-1}$ and (c) $10{ }^{\circ} \mathrm{C} \min ^{-1}$. Once the temperature had reached $100{ }^{\circ} \mathrm{C}$, all samples were finally quenched by immersion in cold water.

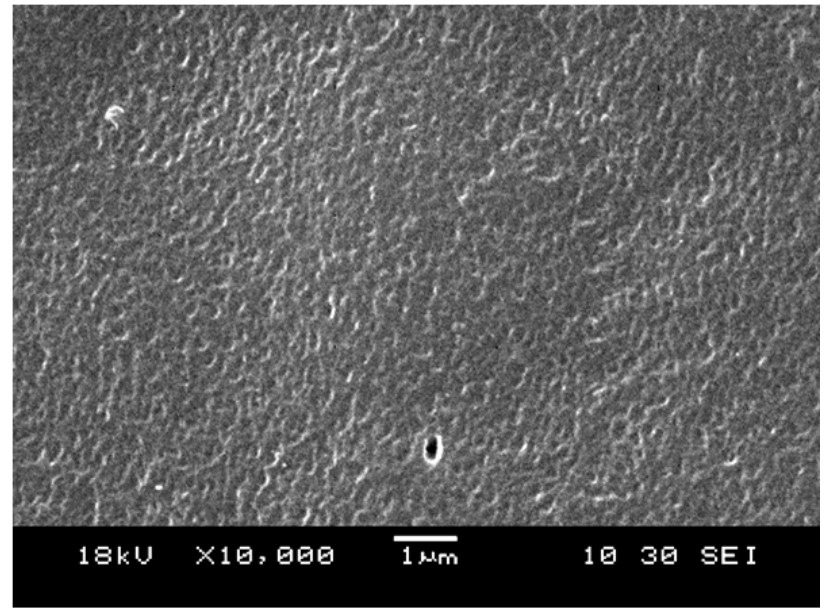

(a)

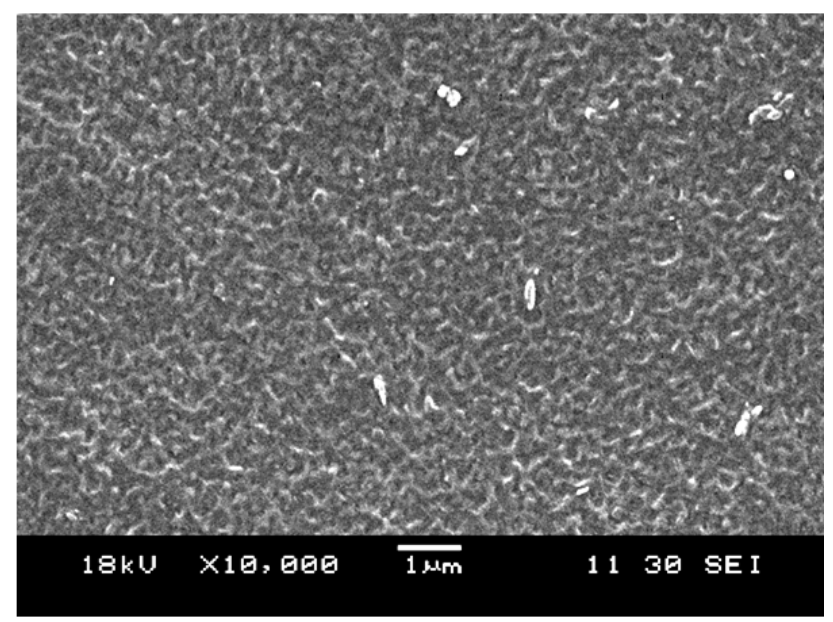

(b)

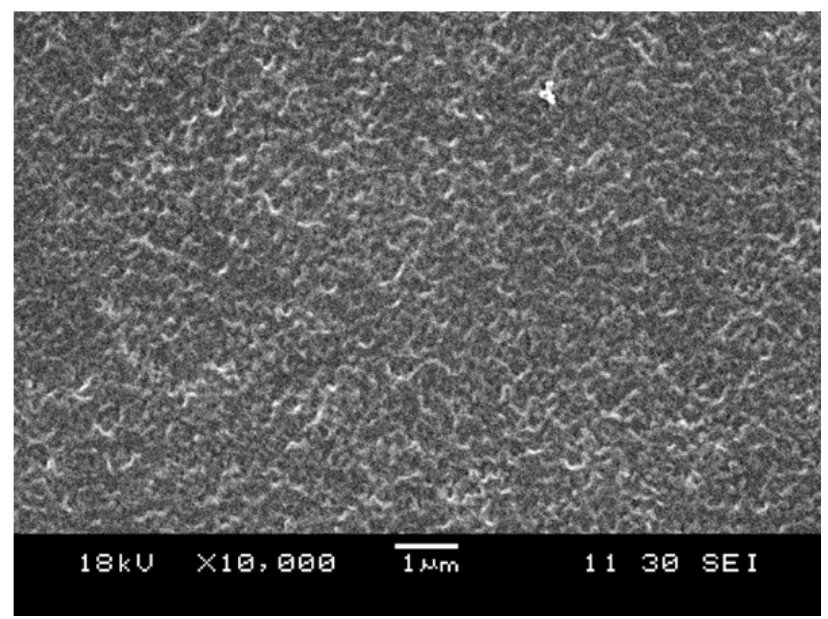

(c)

Figure 9. SEM micrographs showing the morphology that evolved in the mini-cable: transverse cable sections, (a) adjacent to upper cable surface during extrusion, (b) below and adjacent to conductor and (c) adjacent to outer surface below the conductor during extrusion. 


\subsection{MINI-CABLE CHARACTERISATION}

In view of both the electrical and mechanical data discussed above, a blend composed of 50\% iPP and 50\% VERSIFYTM 2200 was chosen for mini-cable production. Figure 8 shows the morphologies that develop in specimens of E2200/50 when crystallized in the laboratory at different cooling rates. These micrographs show a clear coarsening of the two phase texture with decreasing cooling rate and, if the cooling is very slow, aspects of the lamellar texture are also observed. These micrographs can be compared with transverse sections cut from the extruded cable (Figure 9), whereby it may be inferred that all points in the cable have cooled at a rate that is greater than or equal to $10{ }^{\circ} \mathrm{C} \mathrm{min}^{-1}$. The cooling rate appears to have been greater at the outside of the cable than adjacent to the conductor and greater still on the upper surface, presumably due to enhanced convective cooling. However, this conclusion is based solely on the uniformity of the morphology and consequently must be somewhat tentative, since shear forces acting in the extruder may have served to promote homogenization of the blend. Consequently, this point was examined further by DSC. Figure 10 compares the DSC melting behavior of the mini-cable insulation with that of laboratory specimens prepared at various cooling rates. From this, it is evident that the melting behavior becomes increasingly complex as the cooling rate decreases; the simple melting trace obtained from the mini-cable insulation is consistent with an effective cooling rate close to $10{ }^{\circ} \mathrm{C} \mathrm{min}$.

Table 3 shows breakdown data obtained from mini-cables insulated with both the propylene-based blend developed here and, for comparison, a reference mini-cable that was produced using XLPE as part of our previous study [4]. From this, it is evident that none of the undeformed cable samples produced using the propylene-based blend failed before the maximum safe test voltage of $400 \mathrm{kV}$ was reached. In the case of the bent specimens, despite the severity of the deformation (bend radius $6 \mathrm{~cm}$ compared with a total cable diameter of $1.3 \mathrm{~cm}$ ), only three of the specimens failed and two of these failed very close to $400 \mathrm{kV}$. In contrast, the equivalent XLPE-insulated mini-cables all failed at very much lower applied voltages. In isolation, this result is most encouraging. However, comparing breakdown voltages fails to consider geometrical effects associated with differences in insulation thickness between the different mini-cables. Therefore, a statistical analysis of insulation thickness was undertaken for the mini-cables insulated with both E2200/50 and XLPE. For this, both mini-

Table 3. HVDC breakdown results for model cable samples (XLPE reference data are reproduced from [4]).

\begin{tabular}{llllll}
\hline & $\begin{array}{l}\text { No. 1: } \\
\mathrm{V}_{\mathrm{b}}(\mathrm{kV})\end{array}$ & $\begin{array}{l}\text { No. 2: } \\
\mathrm{V}_{\mathrm{b}}(\mathrm{kV})\end{array}$ & $\begin{array}{l}\text { No. 3: } \\
\mathrm{V}_{\mathrm{b}}(\mathrm{kV})\end{array}$ & $\begin{array}{l}\text { No. 4: } \\
\mathrm{V}_{\mathrm{b}}(\mathrm{kV})\end{array}$ & $\begin{array}{l}\text { No. 5: } \\
\mathrm{V}_{\mathrm{b}}(\mathrm{kV})\end{array}$ \\
\hline $\begin{array}{l}\text { Straight } \\
\text { propylene-based }\end{array}$ & $>400$ & $>400$ & $>400$ & $>400$ & $>400$ \\
$\begin{array}{l}\text { Bent propylene- } \\
\text { based }\end{array}$ & $>400$ & 396 & 388 & 270 & $>400$ \\
$\begin{array}{l}\text { Straight XLPE } \\
\text { reference }\end{array}$ & 184 & 168 & 224 & 196 & 196 \\
\hline
\end{tabular}

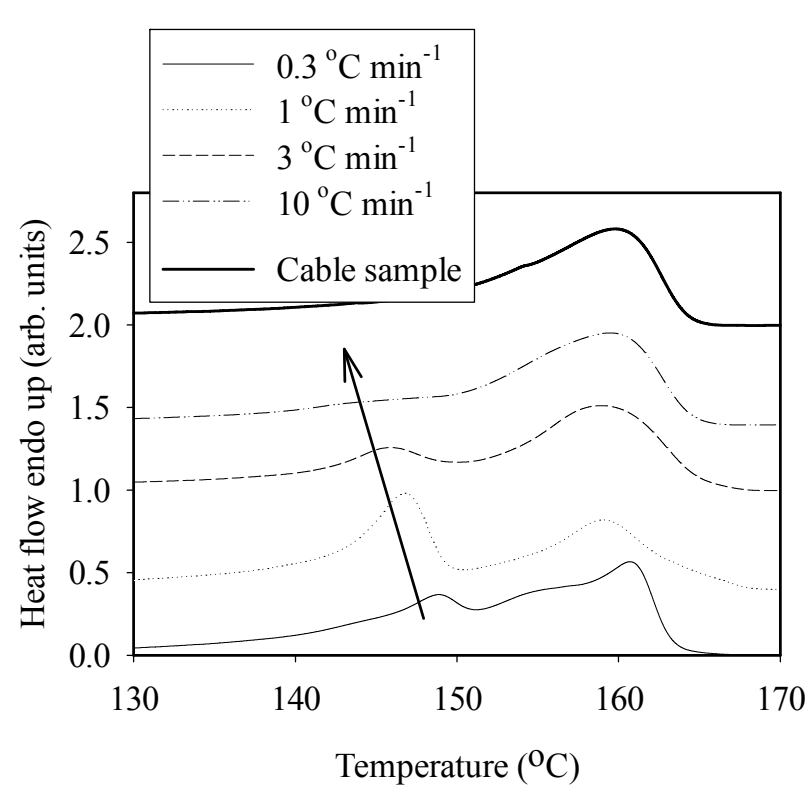

Figure 10. DSC data comparing the melting behavior of samples prepared in the laboratory at the indicated cooling rates (bottom four traces) with that of a specimen extracted from the mini-cable. All data were acquired at a

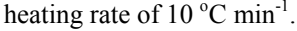

cables were sectioned every $3 \mathrm{~m}$, to give a total of 19 samples per cable type. The insulation was then separated from the conductor in order to measure its thickness at the 6 points corresponding to the conductor strands; that is, at the thinnest points corresponding to the highest internal field. Averaging the resulting thickness data gave values of $3.39 \mathrm{~mm}$ for E2200/50 and $4.34 \mathrm{~mm}$ for the XLPE. The electrical superiority of the propylene-based blend is, therefore, even greater than implied by Table 3 .

Before undertaking the work described above, it was by no means obvious that it would be possible to extrude our selected propylene-based blend into a reasonable cable. While we accept that the testing methodologies fail to take into account many factors that could be important in practical applications (e.g. charge injection from an outer semicon layer will be different from that which occurs here), it is also important to highlight the non-optimal nature of the manufacturing process used here to produce the propylenebased mini-cable. In the absence of any prior experience of such systems, the extrusion parameters, for example, had to be estimated; the DHDA-7707 BK semicon used is formulated from an ethylene-based polymer and, therefore, should be incompatible with the propylene-based insulation. Despite this, the propylene-based mini-cable still outperformed the XLPE-insulated, and much more optimized, analogue, which strongly suggests that, while the precise results presented in Table 3 may be influenced by the particular testing methodology adopted, the potential of propylene-based systems is considerable.

In addition, the data presented in Table 3 were all obtained at room temperature and, therefore, do not provide a direct correspondence with practical cable operating conditions. Nevertheless, examination of Figure 3 reveals that, for our propylene-based blends, $\sim 75 \%$ of the measured breakdown 
strength is retained on increasing the testing temperature from 30 to $120{ }^{\circ} \mathrm{C}$ and that this is irrespective of the choice of copolymer. This implies that the retention of breakdown strength is largely related to the high-melting iPP component of the blend. Indeed, the critical role of the high melting components of designed blends in determining high temperature breakdown performance is further evinced by our previous work on PE-based mini-cables [21]. In this case, increasing the testing temperature from 15 to $67^{\circ} \mathrm{C}$ had little effect on the performance of the mini-cable insulated with the designed PE-based blend; at $15{ }^{\circ} \mathrm{C}$, none of the samples failed prior to the application of $400 \mathrm{kV}$ while, at $67^{\circ} \mathrm{C}$, just two out of five samples failed, at 379 and $352 \mathrm{kV}$. In contrast, the same increase in temperature reduced the failure voltage (Weibull scale parameter) seen in the XLPE-insulated minicables from 196 to $136 \mathrm{kV}$. Taking all the evidence together, we infer that propylene-based blends have the potential to offer greatly superior high temperature performance to XLPE which, in turn, would bring significant network operational benefits.

\section{CONCLUSIONS}

This paper reports the successful development of a new thermoplastic cable insulation from initial laboratory concept, through materials selection and compositional optimization, to the final extrusion and testing of a trial cable. The compositional parameter space of an isotactic polypropylene/propylene-ethylene copolymer blend was explored in terms of the level of copolymer in the blend and the level of ethylene in the copolymer. The optimal composition, based upon laboratory measurements of both electrical and mechanical factors, was found to correspond to equal quantities of the isotactic homopolymer and the copolymer containing $9 \mathrm{~mol} \%$ of ethylene. Increasing the ethylene content in the copolymer and varying the homopolymer fraction away from $50 \mathrm{wt} \%$ resulted in inferior electrical properties and brought no significant compensating mechanical benefits. While the HVDC breakdown voltages determined for a mini-cable manufactured using XLPE as insulation varied from 168 to $224 \mathrm{kV}$, none of equivalent mini-cables produced using the laboratory optimized blend (E2200/50) failed before the maximum attainable voltage of $400 \mathrm{kV}$ was reached. This was despite the fact that the insulation thickness in the mini-cable insulated with the propylene-based blend was somewhat less than that in the mini-cable insulated with XLPE. In the absence of any breakdowns, it was not possible to estimate the HVDC breakdown strength of the blend after extrusion. While this is scientifically disappointing, technologically, it is an extremely promising result. These blends, which perform well electrically, also perform well mechanically, with lower temperature moduli similar to that of XLPE but sustaining a higher modulus than XLPE with a flatter temperature profile up to $120-130{ }^{\circ} \mathrm{C}$. This result and the integrity of the mincable following bend tests reinforce the view that such polypropylene blends represent a new and technologically interesting range of recyclable materials for power cable applications.

\section{ACKNOWLEDGMENT}

The authors would like to acknowledge the support of the Technology Strategy Board, the Engineering and Physical Sciences Research Council, Dow Electrical and Telecommunications and National Grid.

TM Trademark of The Dow Chemical Company ("Dow") or an affiliated company of Dow.

\section{REFERENCES}

[1] Y. Ohki, "XLPE recycling technology in Japan", IEEE Electr. Insul. Mag., Vol. 25, No. 2, pp. 48-49, 2009.

[2] L. Castellani, R.E. Grizante, A. Zaopo and E. Albizzati, Pirelli Cavi e Sistemi S.P.A., US patent US 6410651 (B1), 2002.

[3] S. Belli, G. Perego, A. Bareggi, L. Caimi, F. Donazzi and E Zaccone, "P-laser: breakthrough in power cable systems", IEEE Int'l. Sympos. Electr. Insul. (ISEI), San Diego, USA, pp. 1-5, 2010.

[4] C.D. Green, A.S. Vaughan, G.C. Stevens, S.J. Sutton, T. Geussens, and M.J. Fairhurst, "Recyclable power cable comprising a blend of slowcrystallized polyethylenes", IEEE Trans. Dielectr. Electr. Insul., vol. 20, pp. 1-9 2013

[5] K. Kurahashi, Y. Matsuda, Y. Miyashita, T. Demura, A. Ueda and K. Yoshino "The application of novel polypropylene to the insulation of electric power cable (3)", Elec. Eng. Jap., Vol. 155, pp. 1-8, 2006.

[6] S.J. Dodd, J.V. Champion, Y. Zhao, A.S. Vaughan, S.J. Sutton, and S.G. Swingler, "Influence of morphology on electrical treeing in polyethylene blends", IEE Proc. Sci. Meas. Technol., Vol. 150, pp.58-64, 2003.

[7] G.R. Greenway, A.S. Vaughan, and S.M. Moody, "Morphology and the electromechanical breakdown model in polyethylene", IEEE Conf. Electr. Insul. Dielectr. Phenomena (CEIDP), Austin, TX,USA, pp. 666669,1999

[8] S. N. Kolesov, "The influence of morphology on the electric strength of polymer insulation", IEEE Trans. Electr. Insul., Vol. 15 pp. 382-388, 1980 ,

[9] A. Lustiger, C.N. Marzinsky and R.R. Mueller, "Spherulite boundary strengthening concept for toughening polypropylene", J. Polym. Sci. B: Polym. Phys., Vol. 36, pp. 2047-2056, 1998.

[10] Q. Dong, X.F. Wang, Z.S. Fu, J.T. Xu and Z.Q. Fan, "Regulation of morphology and mechanical properties of polypropylene/poly(ethyleneco-propylene) in-reactor alloys by multi-stage sequential polymerization", Polymer, Vol. 48, pp. 5905-5916, 2007.

[11] F.G. Chang, "Electrical properties of flexible polypropylene based cable insulation materials", J. Mater. Sci., Vol. 41, pp. 2037-2043, 2006.

[12] K.-H. Nitta and M. Yamaguchi, Morphological and Mechanical Properties in Blends of Polypropylene and Polyolefin-based Copolymers, in Polyolefin Blends, Eds. D. Nwabuma and T. Kyu, pp. 224-268, Wiley, Chichester, 2008.

[13] C. De Rosa, F. Auriemma, O.R. de Ballesteros, L. Resconi and I. Camurati, "Crystallization behavior of isotactic propylene-ethylene and propylene-butene copolymers: effect of comonomers versus stereodefects on crystallization properties of isotactic polypropylene", Macromolecules, Vol. 40, pp. 6600-6616, 2007.

[14] R. H. Olley, A. M. Hodge and D. C. Bassett, "Permanganic etchant for polyolefins", J. Polym. Sci. B: Polym. Phys., Vol. 17, pp. 627-643, 1979.

[15] R. H. Olley and D. C. Bassett, "An improved permanganic etchant for polyolefins", Polymer, vol. 23, pp. 1707-1710, 1982.

[16] R. H. Olley, "Selective etching of polymeric materials", Sci. Prog., Vol. 70, pp. 17-43, 1986.

[17] W. Weibull, "A statistical distribution function of wide applicability", J. Appl. Mechs., Vol. 18, pp. 293-297, 1951.

[18] M. Cacciari, G. Mazzanti and G. C. Montanari, "Weibull statistics in short-term dielectric breakdown in thin polyethylene films", IEEE Trans. Dielectr. Electr. Insul., Vol. 1, pp. 153-159, 1994.

[19] W. J. Yin and D. Schweickart, "Dielectric breakdown of polymeric insulation films under ac, dc and pulsed voltages", IEEE Electr. Insul. Conf. (IEC), Montreal Canada, pp. 292-296, 2009. 
[20] K. Yamada, M. Hikosaka, A. Toda, S. Yamazaki, and K. Tagashira, "Equilibrium melting temperature of isotactic polypropylene with high tacticity. 2. Determination by optical microscopy", Macromolecules, vol. 36, pp. 4802-4812, 2003.

[21] C.D. Green, A.S. Vaughan and G.C. Stevens, unpublished work, 2010.

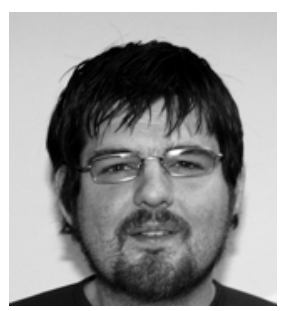

Christopher Green graduated from Southampton University in the UK with a first class B.Eng. degree in electrical engineering and subsequently obtained his Ph.D. in 2008. After spending two years as a post-doctoral research fellow in the Tony Davies High Voltage Laboratory, Dr Green moved to Alstom Grid in Stafford.

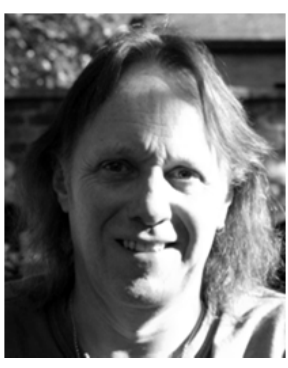

Alun Vaughan (SM'07) has a B.Sc. degree in chemical physics and a Ph.D. degree in polymer physics. After working at the UK's Central Electricity Research Laboratories and spending a period as an academic at The University of Reading, he is now Professor of Dielectric Materials and Head of the Electronics and Electrical Engineering research group at the University of Southampton. He is a former chair of The Dielectrics Group of the Institute of Physics, a Fellow of the Institute of Physics and a Fellow of the IET.

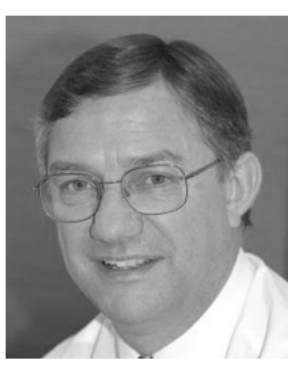

Gary Stevens (M'09) has a B.Sc. degree in physics and a Ph.D. degree in solid state polymer physics from the University of London. $\mathrm{He}$ is founder and Managing Director of GnoSys Global at the University of Surrey Research Park where he is a visiting Professor following his roles as Director of the Polymer Research Centre at the University and Professor of Polymer Science. Prior to this he led research groups at the National Power and Central Electricity Research Laboratories. He is a member of the Institute of Physics, an EPSRC College Member and former Chairman of the Dielectrics Group and Honorary General Secretary of the UK Dielectrics Society.

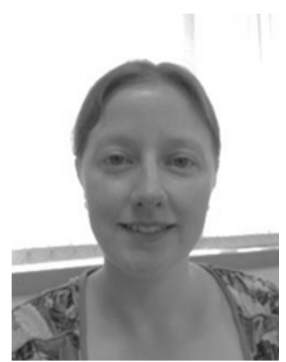

Amy Pye completed her Ph.D. degree in materials chemistry, at the University of Surrey in 2006 developing new materials for electronic insulation through molecular design and assessing structure property relationships (QSPR). She joined Gnosys in 2006 to work on materials development and incorporation of nanomaterials into polymers for electrical applications. Since then she has worked on a number of development projects as well as projects examining the environmental performance of products and schemes.

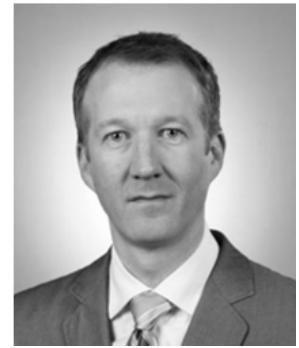

Simon Sutton has a B.Sc. degree in physics and Ph.D. degree in polymer physics both from the University of Reading. After holding several postdoctoral positions, he spent more than 10 years with the National Grid working on cables research before leading teams on Cables Policy, Condition Monitoring and Asset Management. After five years with Dow Wire and Cable, he joined the EPRI as the Power Delivery and Utilization International Technical Executive in EMEA. He is an active member of CIGRE committee D1.

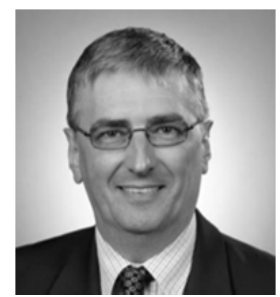

Theo Geussens graduated from Antwerp University in Belgium with a Ph.D. degree in Chemistry. He has been working for over 25 years in various research, technical service and development functions within Dow's Polyolefins business. In 2004 he joined Dow Wire and Cable in Horgen, Switzerland.

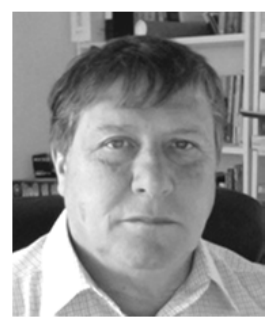

Michael Fairhurst has a $\mathrm{HNC}$ and City and Guilds BTEC in electrical engineering, he has over 40 years' experience within the electricity supply industry in power station, and $\mathrm{HV}$ transmission environment with the CEGB and National Grid. His main center of attention has been the engineering/ management side of the transmission business, focusing on maintenance, construction, refurbishment of overhead lines, $\mathrm{HV}$ cables and managing a number of R\&D projects. He currently leads a team of technical specialists providing technical support to the UK business with regard to overhead lines. He is member of the IET and an active member on CIGRE and ENA working groups. 